\title{
The Study on Beijing Electronic and Information Industry Upgrading Under the Condition of Global Value Chain
}

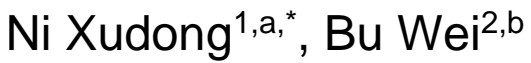 \\ ${ }^{1}$ School of Economics and Management, Beijing Jiaotong University, China \\ ${ }^{2}$ School of Economics and Management, Beijing Jiaotong University, China \\ a15120546@bjtu.edu.cn, bbwei@bjtu.edu.cn \\ *Corresponding author
}

Keywords: Industrial upgrading, Electronic information industry, Beijing.

\begin{abstract}
This paper uses the method of multiple regression analysis to study the relationship among total output, labor input, capital investment and R\&D investment of electronic information industry, and discusses the position of Beijing's electronic information industry in the smile curve and the global value chain. The empirical analysis shows that labor input has the largest contribution to total output among labor investment, capital investment and R\&D investment, which shows further that the current Beijing's electronic information industry is still at the low end of the smiling curve and the global value chain, the labor force is still an advantage of Beijing's electronic information industry integrating to the global value chain.
\end{abstract}

\section{Introduction}

In recent years, the added value of China's electronic information industry increases year by year, electronic information manufacturing industry, software developing industry and information technology services' added value grow increasingly. However, the growth rate of these industries is descending. In 2010, the sales revenue of China's electronic information industry was 7.75 trillion Yuan, including the manufacturing income of 6.39 trillion Yuan and the software industry income 1.36 trillion Yuan. The growth rate of electronic information industry was up to $26.5 \%$. By 2015 , the total annual sales revenue of China's electronic information industry reached to 15.4 trillion Yuan, the manufacturing revenue was high up to 11.13 trillion Yuan. However, the industry growth rate was less than a half of 2010.

Beijing is not only the political and cultural center of China, but international communication center and scientific and technological innovation center as well. Electronic information industry is the pillar industry of Beijing, to promote the electronic information industry to a new level is essential to economic and social development of Beijing.

\section{Literature Review}

The concept of value chain was proposed by Porter in 1985. Porter believes that every enterprise is the collection of a variety of activities in the process of design, production, sale, delivery and support of their products, and all of these activities can be showed as a value chain. Since then, many of the literature study the industrial upgrading under the framework of global value chain from different perspective. Concentrated on the relationship among Latin American industry agglomeration, GVC, industrial upgrading and innovation mode, Elisa, Carlo and Roberta found that in the GVC sector specialization have impacts on the pattern of industry agglomeration and integration of the upgrading mode [1]. Petr, Bolesław and Robert examined the volume changes of three different value-added automotive products in international trade from 1996 to 2006 and found that the main way to upgrade the auto industries in central European countries was foreign direct investment (FDI) [2]. Liu Zhibiao argues that China's industrial upgrading at the strategic level needs to take full account of the breakthrough in the global value chain which is "captured" and "squeezed", and speed up the construction of national values chain (NVC) based on local market 
demand network system and governance structure [3]. Zhang Xiangyang and Zhu Youwei systematically expound the latest achievements of GVC theory in the field of industrial upgrading research. They believe that through individual efforts, collective efforts and industrial public policy support, the industrial upgrading of developing countries can carry on in several aspects [4]. Based on the dimensions of technology and culture, Du Longzheng and Liu Youjin divided the global value chain management model into four types: market type, modular type, relational type and cluster innovation type. They pointed out that through the implementation of cluster innovation the enterprise group can effectively promote the upgrading of local industrial clusters [5].

The research above provides a credible theoretical basis for the research of this paper. However, these studies focus on theoretical analysis, only a small part of the study carried out empirical analysis. In addition, current research on industrial upgrading is mostly focused on the national level, rarely get insight into the regional level. Taking Beijing electronic information industry as an example, in this paper the regional perspective and empirical research are combined to explore the position of Beijing electronic information industry in the GVC.

\section{The Path of Industrial Upgrading under the Global Value Chain}

On the basis of global value chain, the theoretical path of industrial upgrading generally contains: Process upgrading, product upgrading, function upgrading and chain upgrading. For industries that are in the manufacturing sector, they usually upgrade from process upgrading to product upgrading, such as OEM (Original Entrusted Manufacture) to ODM (Original Design Manufacture) and then to OBM (Own Brand Manufacture). The industries that carry out OEM production usually utilize the low cost advantage to integrate into the global value chain production network, thus to achieve process upgrading, and then actualize product upgrading and functional upgrading through investment and R\&D. When the technical level to a certain extent, the transformation, to achieve chain upgrading [6].

Considered the electronic information industry, figure 1 shows the value chain of electronic information industry (the smile curve). Located at the low-end of the value chain is the overall assembly process of electronic products (such as PCs, cell phones and televisions), which often needs a lot of labor. From the low-end to the left is product development and design links, this process usually requires massive $R \& D$ investment and the participation of high-tech talents, with higher production added value. From the low-end to the right is product marketing and aftersales links, this process is no longer limited to the sale of products, including services, which can obtain a larger market, while improving the competitiveness of products with higher added value through the creation of brand effect.

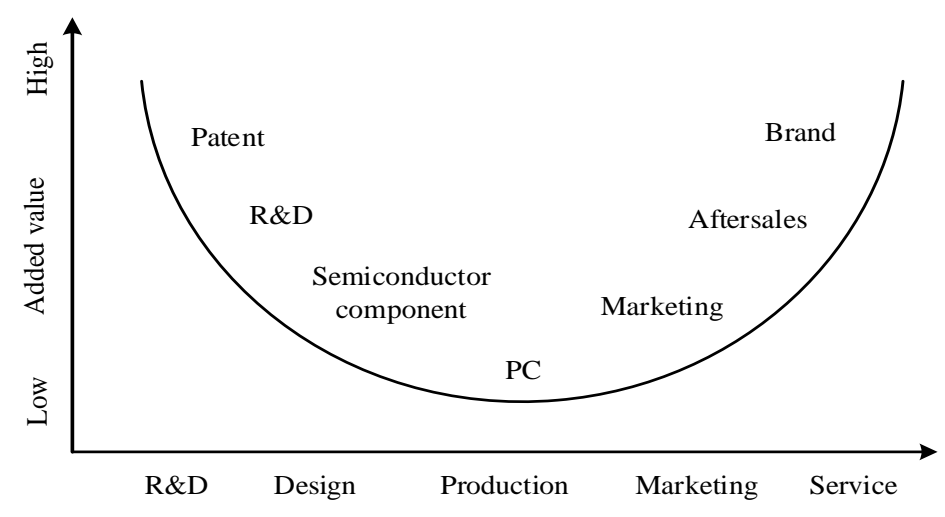

Fig 1. The value chain of electronic information industry (the smile curve).

\section{The Position of Beijing Electronic Information Industry in the Global Value Chain}

This part uses the method of empirical analysis to find the position of the electronic information industry in Beijing in the global value chain and smile curve. 
For the electronic information industry, labor, capital and technology are the elements of productive activities that require significant investment. In general, depending on the input of various factors of production, the industry can be categorized into a certain kind of factor-intensive sectors, such as traditional division of labor-intensive industries, capital-intensive industries, technology-intensive industries, and so on.

This division is not immutable. For a specific industry, based on its elements input in production activities, it will be divided into a corresponding intensive industry. For example, given that the industry's production activities need to invest a great deal of labor, it can be classified into labor-intensive industries. However, after a few years, with the development of productivity, its input in production activities has changed, such as with the progress of science and technology, a large number of labor used in original production activities has been replaced by machine, then this industry no longer belongs to labor-intensive industries, and capital-intensive industry is more suitable.

In fact, with the passage of time and technological progress, the attribution of the industry transfers from a kind of labor-intensive to capital-intensive, its nature has also changed. This process is also the process of industrial upgrading, which is mainly for the improvement of industrial structure and production efficiency. Machine can produce more efficiently than manpower production, thus providing higher added value for the industry. Therefore, the enterprises in the industry are willing to use machines to replace labor forces and invest in the purchase of production machinery and equipment. The first industrial revolution replaced a large amount of manpower with a large number of machinery; the technological innovations emerged in the second industrial revolution brought the machine's productivity to a higher level again. For the industry, these two industrial revolutions were unprecedented in the process of industrial upgrading. Therefore, this change in the structure or feature of production is also a measure of industrial upgrading.

This progress is also shown on the smile curve in figure 1. Every position on the smile curve corresponds to a specific part of the industry, and this part corresponds to a specific factor-intensive sector. For instance, the bottom of the smile curve corresponds to the assembly part in the industry, which do not need to invest too much capital and technology usually. Industries engaged in this sector are usually labor-intensive industries. Since each position on the smile curve corresponds to a factor density, it is also feasible to measure the position of industries on the smile curve based on the factor density of an industry. Once the position on the smile curve is determined, the position of the industry in the global value chain is obvious, which lays the theoretical foundation of this paper.

The production function constructed in this paper is given by Eq. 1. Variable OUT means the total output value of electronic information industry in Beijing, LAB is on behalf of the labor force, CAP represents the capital investment and TEC is science and technology investment. The coefficients represent the degree of contribution of each variable respectively. And subscript $i$ represents time.

$$
\log \mathrm{OUT}_{i}=\alpha_{0}+\alpha_{1} \log L A B_{i}+\alpha_{2} \log C A P_{i}+\alpha_{3} \log T E C_{i}+\varepsilon_{i}
$$

In this paper, the total output of the electronic information industry (OUT) in Beijing is measured by main business income. The measure of labor force (LAB) is the average number of employees, and the measure of capital investment (CAP) is the amount of investment, R\&D investment (TEC) is used to measure the internal expenses of R\&D funding. Considered the correlation coefficient between variables, there is a certain degree of correlation between the independent variables. To solve this problem, this paper uses the stepwise regression method to modify the model. The regression equation is given by Eq. 2 .

$$
\log O U T=2.447+1.956 \log L A B+0.074 T E C
$$

According to the results of the regression, the average number of employees plays a key role among the three influencing factors, which indicates that for the electronic information industry in Beijing, the greatest contribution to the total output is made by labor input, rather than the $R \mathrm{D}$ 
investment and capital investment. Results also shows that the current electronic information industry in Beijing is still a labor-intensive industry, not technology-intensive industry or capital-intensive industry.

\section{Conclusion}

The position of Beijing's electronic information industry in the global value chain determines that the upgrading of electronic information industry still has a space. At present, the main problem of the electronic information industry in Beijing is the dependence on the labor force, and the advantages of capital and technology research are not fully applied to the industry. Cheap labor advantage is determined by the current basic national conditions in China, and in the next few years it will not happen to change, so it's vital to take full advantage of this advantage, which most developed countries do not have. On the other hand, foreign enterprises at the high value-added location still firmly control the core technology, which set barriers for enterprises at low value-added from developing countries to consolidate their controlling. Therefore, China's enterprises have to seek breakthroughs in product innovation and production process innovation, and constantly develop new products, develop new production processes, make full use of capital and technology research and development advantages, thus to achieve product upgrading and process upgrading. China has a large market, with a diverse demand, which is also a great advantage for the product innovation.

\section{References}

[1] Elisa Giuliani, Carlo Pietrobelli and Roberta Rabellotti. Upgrading in global value chains: Lessons from Latin American clusters. World Development, vol. 33, pp. 549-573, 2005.

[2] Petr Pavlínek, Bolesław Domański and Robert Guzik. Industrial upgrading through foreign direct investment in central European automotive manufacturing, European Urban and Regional Studies, vol. 16, pp. 43-63, 2009.

[3] Liu Zhibiao, Zhang Jie. From integrating into global value chain to build national value chain: Strategic thinking on China 's industrial upgrading. Academic Monthly, vol. 41, pp. 59-68, 2009.

[4] Zhang Xiangyang, Zhu Youwei. Research on industrial upgrading based on global value chain. Foreign Economics and Management, vol. 27, pp. 20-27, 2005.

[5] Du Longzheng, Liu Youjin. Research on industrial upgrading and cluster innovation in global value chain. International Economics and Trade Research, vol. 23, pp. 66-70, 2007.

[6] Zhang Yanhui. The empirical analysis of the Yangtze River Delta under the global value chain. Shanghai Journal of Economics, vol. 3, pp. 51-59, 2010. 